\title{
Case Study : 'Odin' to 'Trade Tiger' at Sharekhan Pvt Ltd -a shift in Trading Platform
}

\author{
Prof. Prabhavathi .C
}

\section{Background of the Case}

Managing risk today requires a dynamic approach. Trading in the secondary market requires a highly integrated risk management structure. Integrated risk management structure which will assess and evaluate the risk associated from trade origination to settlement. Recognizing this need Sharekhan Pvt Ltd has developed personalized software as trading platform that will take care of the above need, known as "Trade Tiger". Trade tiger has substituted the ODIN software which is used as the trading platform by Sharekhan and many other stock broking firms. This case focuses on the issues related to the needs, benefits and also the pitfalls of trade tiger as compared to that of ODIN. To understand the above objective, the case covers the trading operations control and some risk management issues in trading operations.

\section{Sharekhan Pvt Ltd}

Sharekhan is a retail financial services provider with a focus on equities, derivatives and commodities brokerage execution on the National Stock Exchange of India (NSE), Bombay Stock Exchange (BSE), National Commodities and Derivatives Exchange of India (NCDEX) and Multi Commodity Exchange of India (MCX). Sharekhan provides trade execution services through multiple channels - an Internet platform, telephone and retail outlets and is present in 225 cities through a network of 615 locations. It provides a complete lifecycle of investment solution in Equities, Derivatives, Commodities, IPO, Mutual Funds, Depository Services, Portfolio Management Services and Insurance.

\section{Trading Operations Control}

An insight into trading operations control gives the base towards understanding secondary market trading mechanisms. It explains the trade life cycle, front office controls, middle office controls and back office controls.

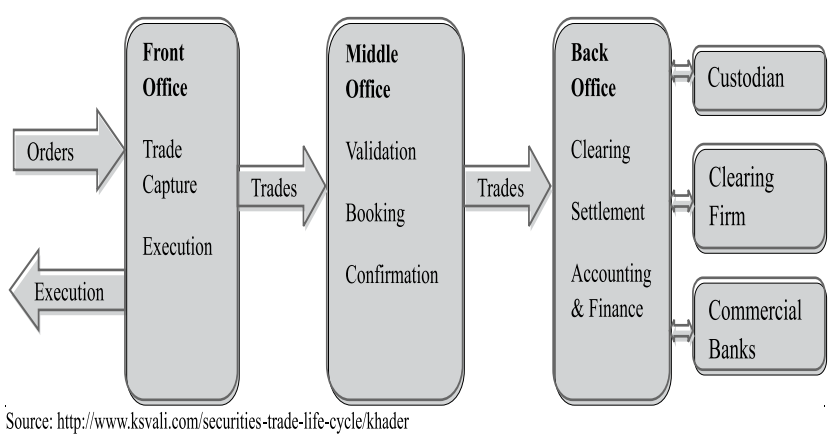

\section{A. Trade Life Cycle}

Trade life cycle is process from trade origination to trade settlement. This process includes trade origination, trade execution, trade validation, trade confirmation, clearing and trade settlement. The diagram below shows the flow of activities in the trade life cycle. 


\section{B. Front Office Controls}

The Front Office forms the stage where the trade gets initiated. Here, the order gets placed and the entity will price the instrument and give the quote to the counterparty. If the counterparty agrees to the details of the trade and is willing to enter into the deal, the trade gets executed. The trade is then captured in the trading desk usually using a deal capture system. The deal capture system validates all the necessary trade economics before assigning a trade reference number. Subsequent trade events like amendment, cancellation would refer to the trade with the help of the identifier. An acknowledgement is being sent to the counterparty with the trade details who confirms it back.

\section{Middle Office Controls}

The Middle Office plays a vital role in the exception management. The trade gets enriched by static data like the standard settlement instructions of the counterparty, Custodian details, City holidays, etc. Such static data details are important for the completion and settlement of the trade. The allocation of the trade is done in the Middle Office and finally the trade is being pushed to the Back Office and the trade goes live.

\section{Back Office Controls}

The Back Office is the back bone of the entire life cycle of the trade. The Back Office by and large deals with the operational activities like record keeping, confirmation, settlement and regulatory reporting.

\section{Risk Management Issues in Trading}

In view of a stock broking firm, risk management issues in trading operation is, majorly concerned with clearing and settlement systems.

Clearing and Settlement systems are systems providing the process for transferring funds and securities. The arrangements for clearing and settlement systems should provide the expeditious verification of a trade. Fully automated links between the trading system and settlement system will in general assist in such verification.

It is essential that the financial stability, consistency, transactions of the participants in clearing and settlement is scrutinized. This minimizes the risk of failure of participants and overall risk to the systems. The transaction details for every individual customer should be made available at ease and should be promptly retrievable on the event of default. This would make information sharing and trading as transparent as possible.

The primary focus of risk management system of a broking firm is to manage the margin requirement and risk control measures. Stock broking firms should design margin requirements with adequate margin in trading. In turn, this provides sufficient funding to likely trading exposure among their clients and a clear edge in terms of risk free trading. The firm should ensure that their system consistently works on gaining better margin and restoring them. With the intention to retain trust and built confidence among the investors.

The other risk management issues related to risk control are circuit breakers, position limits, price limits, trading halts, capital adequacy, lending limitations, insurance coverage, back-up systems and guarantee funds.

\section{ODIN}

ODIN is Financial Technologies flagship product. It has been the 'Trading Platform of Choice' for various leading broking firms with major market share. It provides real time connectivity to the multiple exchanges offering highest order execution speed and operational stability.

ODIN makes trading easier on multiple markets through the use of a single application. This is the Multi-Exchange, Multi-Currency, and Front Office trading risk management system. It incorporates appealing features and works on advanced technology which facilitates higher accessibility, ensuring speedy performance and advanced risk management. 


\section{Value Proposition}

- A single application which provides multi-exchange front office securities trading platform for equities, derivatives and commodities markets.

- It provides real time connectivity to the exchange and back office system with faster inter-segment trading.

- It offers a complete trade and system audit trail, real time price and position information and risk monitoring at all levels.

- Fully customizable views from all levels besides extensive search and filtering options.

\section{Need for a personalised online trading platform}

In the age of internet, where everything is going online, stock trading had also gone online. Thus in securities trading, we have offline trading and online trading. Offline trading is buying and selling of shares in stock exchanges through a broker or a call. Online trading facilitates trading through internet by the trader. Online trading has increased trade volume and number of investors trading in stock markets with its benefits.

The onset of online trading changes the traditional value proposition of trading by allowing online trading brokers to supply investors with rich, interactive information in real time including market updates, investment research and robust analytics.

Sharekhan recognizing this need for online trading would provide an integrated trading experience that combines execution with interactive analysis and as ODIN being an offline trading platform, developed personalized software - Trade Tiger. Trade Tiger is an online trading platform established by Sharekhan in 2005.

\section{Trade Tiger}

Trade Tiger is an advanced online platform with live streaming quotes for NSE, BSE MCX and NCDEX.

This provides a one stock single screen through which multiple trading like equity, derivatives and commodities can be transacted online. Order execution is immediate and clients get order and trade confirmations immediately.

An intense platform with customized market watches to enable the users to make quick decisions. The user can create and benefit from as many market watches as possible. There are some pre-defined markets matches like sectoral market so that the user need not do much to get the right script's to be traded. Clients holding multiple accounts can create their own market watches. The layout can be customised according to the users' preference and saved to reduce the hassles of creating a fresh screen layout every time the user logs in.

Users can sight through the intra day tic-by-tic charts. This provides entire information for investment decisions. A wide range of technical analysis tools are provided to enhance trading decisions. Trade Tiger makes easy accessibility of market summary and online reports. It is also backed up with a separate dedicated customer service team.

\section{Value Proposition}

- Advanced online platform which provides trading in NSE, BSE, MCX and NCDEX.

- One stock single screen through which multiple trading like Equity, Derivatives and Commodities can be transacted online.

- Intense Platform with customized market watches.

- Customized layout according to user's preference.

- Wide range of technical analysis tools to enhance trading decisions. 
- Easy accessibility of market summary.

- Backed up with a separate dedicated customer service team.

\section{Lacuna of Trade Tiger}

Trade tiger being a personalized, advance trading platform for Sharekhan, the challenges in using this platform continues. We see that, still the traders have to relay on ODIN which happens to be an offline trading platform. The default software which is available with the online trading platform helps in providing real time information to the main or corporate offices which infact is hindsight because the details that have been discussed during the transaction would not be available at the base level. Trade tiger though facilitates huge volumes; the secondary backup comes from ODIN during the period of none availability based on technical issues.

\section{The Road Ahead}

"Constructive use of new technologies has always contributed positively towards improving human life standards and economy of the country". Thus establishment of Trade Tiger by Sharekhan to enable a single screen online trading platform has its own pros and cons. How should the organization make effective usage of the technology and overcome the shortfalls of this new technology?

\section{References}

1. Jean-Claude Riss, Bridging the trading life cycle with integrated risk management software, Back Office Focus, September 2003.

2. www.ftindia.com/solutions/.../ ODIN $\% 20$ case $\% 20$ studyShareKhan. pdf

3. http://www.sharekhan.com/tradetiger

4. http://en.wikipedia.org/wiki/Enterprise risk_management

5. http://www.investopedia.com/articles/ trading/09/risk-management.asp

6. http://www.ksvali.com/securities-tradelife-cycle/khader

7. http://www.shnshare.org/on-line-trading\%E2 \%80\%93-an-overview 